\title{
Rehabilitation Programmes of Large Scale Irrigation Projects - An Opportunity to Alter the Farmers' Role in Irrigation Water Management
}

\author{
Mahinda Panapitiya, Lalitha Padmini Senevirathne and S.K.Hewadewa
}

\begin{abstract}
Past experience in Sri Lanka shows that a need for a major rehabilitation of irrigation systems arises at 20 to 25 Years cycle. Usually these rehabilitation programs are implemented by borrowing funds form international donors such as World Bank, EU, JBIC etc. However in time to come, the dependency on such outside funding sources is questionable in view of the trends in lending criteria for countries such as Sri Lanka. Therefore it is very essential to plan such rehabilitation programs guarant long term self-sustainability beyond the rehabilitation phase.
\end{abstract}

One way to address this challenge is to introduce management tactics which would facilitate harnessing of human resources available within the farming community for the operation and maintenance of the irrigation infrastructure. If properly planned, the rehabilitation phase provide a good opportunity to initiate such a program. This paper describes a Water Management Programme (Water Quota system) which was implemented in System H of the Mahaweli Project with the objective of tapping the human resources available within the Farming Community strategically to address the challenge. This program was implemented during 1998-2003 as a parallel activity with a rehabilitation program under Mahaweli Restructuring and Rehabilitation Project (MRRP) in System H of Mahaweli Project As a result of this program water duty drops down with time after the year 2000 (Year of introducing the Water Quota System). Within 4 Years period from 2000, average water duty came down to 0.85 Meters from 1.2 Meters.

\section{Introduction}

The main goal of an infrastructure rehabilitation program of irrigation projects developed for mass scale human settlement such as the Mahaweli Project can be summarized in to following categories.

- Structurally sound infrastructure to last long

- Hydraulically adequate canal system to deliver right quantity of water at the right time to the farms

- Institutionally capable user groups to Operate \& Maintain the System

Irrigation System is a man made engineering product like any other technological innovation such as a Motor Vehicle. For any man made product, the operation of the product according to guidelines and its regular maintenance, are essential pre-requisites required for its long term sustainability. Reliability of the product in delivering its intended service and the ownership feeling attached to the product by the user also play a big role in assuring its long-term sustainability. The Same rule applies to Irrigation Systems too. However in the case of irrigation systems where the owner is not an individual but a community consisting of a large number of farmers, the community as a group should have the feeling of ownership to the system. Therefore, in large scale irrigation systems, a strong institutional setup among user groups is a necessary pre requisite for its proper functioning. At the same time the system should be reliable enough to deliver the irrigation water to individual farms at the right time in the right quantity. The creation of the feeling of the group ownership would then be an automatic result of the reliability. The Rehabilitation phase of irrigation systems can strategically be utilized as an opportunity to achieve reliability in delivering water to individual farms while rehabilitating irrigation hardware.

Eng. Mahinda Panapitiya, MIE (SL) B.Sc (Eng), Peradeniya, M.S (Utah State University), USA, Presently, Managing Director ofDavids $\mathcal{E} M$ Engineering (Pvt) Ltd

Eng. (Mrs.) Lalitha Padmini Senivirathne, MIE(SL), M.Sc (Trondhein-Norway) Presently, District Program Manager (LiSSP) Anuradhapura

Eng. S.K.Hewadewa, AM(IESL), B.Sc (Eng), Peradeniya, Presently, Irrigation Engineer - PEACE Project, Anuradhapura. 


\subsection{Mahaweli Restructuring and Rehabilitation Project (MRRP).}

Under Mahaweli Restructuring and Rehabilitation Project (MRRP) funded by the World Bank, Irrigation Network in System H was rehabilitated during the period from 19982003. The Implementation agency was the Mahaweli Authority of Sri Lanka (MASL). The total extent of the irrigated land rehabilitated under MRRP was about 30,000 Ha. The land ownership of the project is $1 \mathrm{Ha} /$ Farmer.

The Structural Improvement of the Irrigation Canal network was the main component which consumed a large amount of rehabilitation funds under the MRRP. One noteworthy feature of MRRP was that the enhancement of the Water Management capabilities of farmers was also treated as one of the major components in addition to structural improvements.

\section{Existing Management Environment before MRRP}

There are 3 hierarchical levels of canals within the irrigation distribution system in System H.

1. Main System (Main Reservoir, Main Canals and Branch Canals)

2. Secondary System (Distributay Canals)

3. Tertiary System (Field Canals)

At the time of the rehabilitation under MRRP, the main system was administered by the MASL while the farmers had been organized at Tertiary Level called Field Canal Farmer Organizations (FCFO). FCOF,s had been federated into Distributary canal Organizations (DCFO). The Existing practice of issuing water was based on a Top Down approach where the MASL issues water from the main systems to the DCFO,s according to a schedule prepared by the Irrigation Engineer of the Main System. The Farmers as a grov: under each Distributary Canal (DCFO) have o distribute water among themselves accordir io the releases from the Main System. As such the Farmer Groups (DCFOs) did not have any command over the Rate, Duration and the Frequency of receiving water from the Main System because the main canal was operated on rigid pre-arranged schedules decided on by the Main System Operator. As a result, the role to be played by the DCFO,s in managing the water at
Distributary canal level and Tertiary levels had been very minor because DCFO did not have any kind of command over receiving water from the main water source (Main Canal).

\section{Irrigation System Designs}

Similar to Technical Assumptions, there are Social Assumptions required for the design of irrigation networks in large scale irrigation systems. One such assumption is that at one point down the irrigation canal network, canal operation would be taken over by the farmers and that they as a group will have to manage it in a decentralized mode beyond that point. Therefore organizing the farmers in to decentralized groups is the key to the successful operation of an Irrigation system.

In 70's farmers were decentralized in to groups at Tertiary Canal levels (F-Canal) and the O\&M of Secondary Canals and the Main systems were undertaken by the government. At that time the membership of the farmer group was limited to around 10 farmers organized at Field Canal Level. However in late 90's the membership of the farmers group had to be expanded out to a Secondary Canal level called Distributary Canals, where the membership is around 100 . Therefore in the current scenario, strategies to form cohesive groups having a large membership need to be introduced by organizing them in to Distributary Canal Farmer Organizations (DCFO)

\subsection{Ancient Irrigation System Design verses Modern Design}

It is very interesting to note that in ancient irrigation networks which were in existence in the same area before Mahaweli Design were introduced in 1977, farmers were enjoying the command over the water source. In the ancient system the water supply from the Main Canal called Yoda Ela had been made flexible by incorporating cascade tank systems into the irrigation distribution system. In the modern design water is issued to the farms directly from canals and therefore from the user point of view, the water source is dynamic in nature. In contrast, the ancient design tried to keep water source stationery as much as possible by storing it in online irrigation tanks (Cascade System) before it reaches farm level. The Stationary nature of the water source provides flexibility 
for farmers to extract water from the source as and when they need it. As a result the farmers as a group under ancient village tanks enjoyed the full command over the Rate, Duration and Frequency of the water supply from the source. Therefore the cascade design had also indirectly facilitated the formation of cohesive user groups (villages) capable of managing water in a decentralized manner. .

As a result of decentralization, the responsibilities of the farmers related to $O \& M$ as a group had been more accountable than that of the farmers under the modern system. The Irrigation Tanks in the ancient design were the nucleus around which villages were formed. In contrast, modern designers perceive those small tanks as water spreads which inundate cultivable lands and therefore need to be demolished. The Main objective of the modern design was only food production using every inch of land. On the other hand ancient designers had envisaged the transformation of the target area into a wet zone where irrigated agriculture is only one component of a total picture. Social and Environmental improvements had also been considered as inbuilt goals of the ancient design.

\section{Water Quota System}

The Water quota system which was introduced in System H is an effort to simulate the ancient system to a certain extent. Since the modern design had overlooked the need for online storages, efforts were made to simulate a similar situation by introducing a water quota system.

In the newly introduced water quota system, the farmers under each secondary canal called DCanal, were allocated a fixed volume of water for the season at the beginning of the cultivation. A water ordering system was then introduced so that the Farmers as a group can order water from the Main Canal as and when they needed it. The Main canal was operated on a demand basis rather than on a pre-determined schedule. Based on the volume of water allocated for the season to the individual DCanals, the area to be irrigated and the type of the crop to be grown were decided by the farmers themselves. Farmer groups were regularly updated on the quantity remaining in their individual quota which was available for the rest of the season. In other words, a condition was created which was similar to the situation experienced by the farmers under a village tank where as a group they were aware of what they had in the tank for the rest of the season.

Before the new water quota system was introduced, MASL was making all the decisions regarding the area to be irrigated and the crop to be grown for the cultivation season. However under water quota System, MASL decides only the volume of water available for the season. It is up to the farmers under each Farmer Organizations at Distributary Canal (DCFO) to decide on the crops to be grown and the area to be under irrigated agriculture. MASL then operated the Main System in a flexible manner to meet the variable demands from user groups. The Role of the MASL was to facilitate the above process by updating water consumption data weekly so that each DCFO would know the volume of water available for the rest of the period at any given time of the season. In other words instead of Physical Storages in the form of village tanks, a virtual storage tanks were created at the head of each D- canal.

\subsection{Water Management}

In order to practice the above water ordering system, it was necessary to calibrate all the off takes from the Main System and train the farmers about Water Measurement methods. Therefore the Calibration of off takes at delivery locations to individual decentralized units and training of the farmers to measure water, were also main components implemented under MRRP. The Farmers were also trained to compute water requirements for different combinations of crops and to make estimates for areas to be cultivated to suit the volume of Water allocated into their individual territories.

\section{Achievements after introducing the water quota system}

Under Water Quota System Farmers had the freedom to alter the rate, duration and the frequency of application, subject to the allocation limit and canal capacities. As a result, the rainfall was also effectively utilized because the farmers themselves were motivated to close the canal system during rains to save the individual allocations. Farmers were also motivated to adopt their own farm water management methods to save water. 
As a result of above practices adopted by the farmers after the introduction of the Water Quota System, Project Level Duty was gradually reduced with time. This paper analyzes the trends in the reduction of water duty during Maha Season for selected Blocks in System H3, H4 and H5 under Kalawewa Reservoir.

As indicated in the following Graphical Presentation duty began to come down with time after the year 2000 (Year of introducing the Water Quota System). Within the 4 Year period after introducing the water quota system, average duty came down to 0.85 Meters from 1.2 Meters in 2000/2001 Maha.

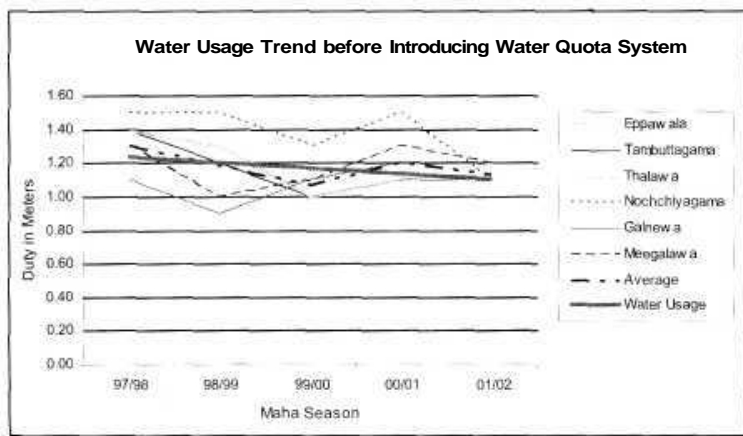

Figure - 01

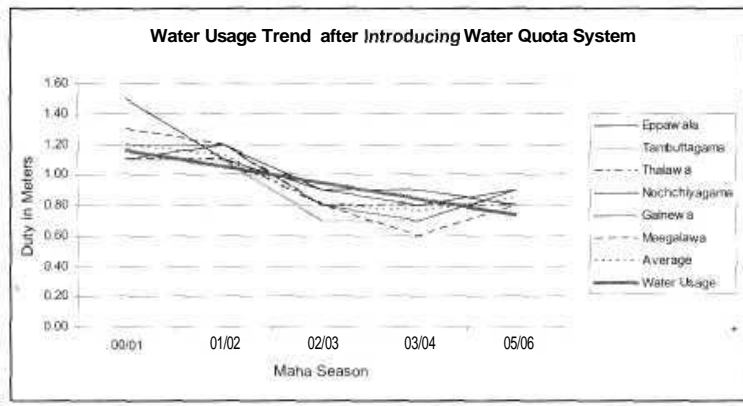

Figure - 02

Irrigation Hardware Rehabilitation under MRRP was one major factor which contributed to this improvement. In addition, the newly introduced water quota system also contributed to the positive trends as demonstrated by above graphs because as indicated in Fig 3, Water Savings against the seasonal allocation (the difference between seasonal allocations by the MASL and the actual water usage by the farmers) increased gradually with time after the introduction of the water ordering system.
Before the year 2000, farmers made a request for water only when there is not enough water in their D-Canals i.e. during rotation periods allocated to them by the MASL. However with the new water quota system, farmers' requests for water were based on the quantity of water allocated by the MASL to each DCFO. The seasonal volumetric allocations at the beginning of the cultivation season to each DCFO, was the basis for requesting water. This basis was a kind of informal agreement between MASL and the DCFO. These agreements define their responsibilities to each other. Therefore there is always accountability associated with any request originated by the farmers for water. As a result, the DCFOs always tend to save their

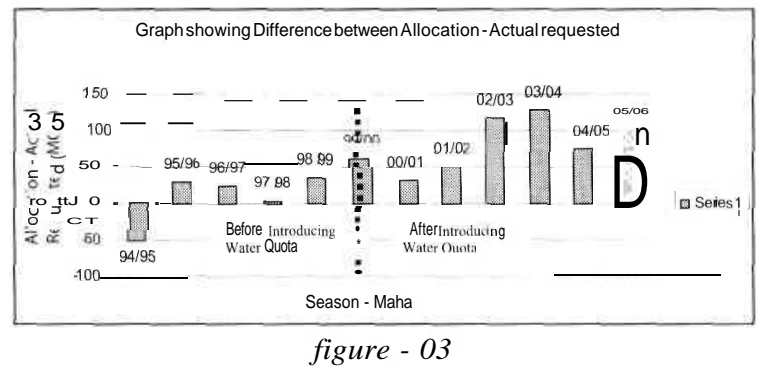

quota to meet possible water scarce situations of the rest of the season.

One other feature indicated by the above illustration is that while practicing the water quota system, farmers educated themselves through practice to manage water as a measurable resource. The Importance of measuring water at the entry into the territories under their command (D-Canal) became an essential skill for them to deal with MASL. A trust was also developed between the 2 main stakeholders of the program namely MASL and DCFOs because there was always a method to asses the obligations to each other through a volumetric quantification. As indicated by the above graph the improvement was a gradual process because farmers became skillful only with experience.

According to the World Bank report on MRRP (2003), Water Quota was the best water management program in the South East Asia ${ }^{1}$. However, at the time of introducing Water Quota System in 2001, it was criticized even in

1 World Bank Report (2003), Aid Memoirs, MRRP Implementation Progress Review, June 2-12,2003 
national papers as a method to introduce Water Rights which is still a controversial issue in the country. The Allocation of water resources on a volume basis is the main objective of the Water Quota system. The need for Water Quota system arose as a management tool to increase water use efficiency. The Outcome of the data analyzed for 15 years in the project area indicated a $30 \%$ increase in the water productivity and a $36 \%$ increase in farmer income ${ }^{2}$ after introducing the water quota system.

Even in the traditional system of Village Tanks, water was treated as a limited and measurable commodity. The Capacity of the tank is the estimation for farmers to gauge the volume of water received to each village from the main system (Yoda Ela). Instead to a village tank, in the case of Water Quota System, water is issued to DCFO on volumetric basis from the Main System to each D-Canal. Therefore the Operation of the Main system simulates the condition of combinations of village tanks located along a contour.

\section{Advantages and proposed improvements}

As explained above, the Water Quota system is presently being implemented thorough informal agreements. If the agreement between the MASL and DCFO is a formal contract with a legislative backing, the Water Quota System will then naturally evolve in to an efficient management tool with time while improving the Farmers' role in managing water. However in the absence of a clear water policy on water rights it is difficult to implement the Water Quota System in such a progressive mode. If the system is formalized with a legislative backing, incentives also can be introduced for the farmer groups who are using water efficiently. In fact those incentives will naturally evolve itself with time with the experience of the farmers in practicing the Water Quota System. Some of the potential benefits of the new system are as follows.

\subsection{Introduction of Incentive Schemes for farmers}

One important benefit of introducing Water Quota System was that the MASL was able to make use of human resources available within the farming community for Water Management at Secondary and Tertiary level. This benefit can be further enhanced if the MASL can introduce incentives for the farmer organizations who consume water below the allocated quota. For example, MASL can operate the Main System in such a way that the water saved from the allocation for a particular season can be made available as an extra grantly for the next cultivation season thereby motivating the farmers for better management. In this process, water quota can be allocated on an annual basis at the beginning of the Maha (Wet) cultivation season so that farmers who saved water by effective utilization of rains or by adapting efficient farm water management techniques, would become entitle for an additional water quota during the subsequent Yala (Dry) Season. This situation is similar to the condition of village tank irrigation. For example, if the farmers effectively utilized rainfall in Maha rainy season in a village tank system then the farmers can use saved water in the tank during the next Yala dry season.

\subsection{Management Improvements}

In practicing Water Quota system, the Main Canal needs to be operated in a flexible manner so that it can meet the variable demands from the farmers without much time lag. The Operation of the Main system should simulate the condition of combinations of village tanks located along a contour. Modern communication systems can effectively be used for this purpose.

Another advantage of Water Quota System is that it generates area wise Data Base on Water Consumption. Therefore the areas of high water consumption can also be identified so that funds for improvements can be allocated in a more realistic manner. In addition this Data Base will be very useful in managing conflict situations that arise during water scarce periods. Performance indicators can also be developed for Water Management Staff because area wise water use efficiency can be monitored from the data base.

2. Bulk Water Allocation Concept for improving Water Productivity - by Bandula Gunarathne- Water Resource Research in Sri Lanka - Symposium Proceeding of the Water professional's day (Oct 4, 2003) organized by PGIA, University of Peradeniya 


\subsection{Sharing the risks}

In the top down approach practiced earlier, MASL had to bear the sole responsibility for any crop damage in water scarce situations. However in practicing the water quota system farmers have to play a main role in making decisions related to water management. Therefore the Water Quota system could even be further improved to quantify those risks in such a way that MASL can share the risks related to water scarcity with the farmers. For example if the MASL can prepare the seasonal water allocations incorporating the probability indices into the quota, farmers would automatically get pushed of into a situation where they also have to share the risk in crop failures because they are responsible for deciding the area to be cultivated.. For example, the farmers who opt to take high risks will cultivate more area than farmers who do not want to take high risk.

\subsection{Awareness Building}

Presently the government is trying to introduce legislation related to water rights without any success. In order to introduce any new legislation, the need should ideally be originated from the user and it should also not be perceived as an imposition from the top. If the water quota system is practiced in its true spirit, it would act as a catalyst for farmers to become aware of the importance of having legal backing to manage water. This awareness would then create the required conducive environment for the government to introduce the legislative systems related to water resource conservation.

\section{Designing of Future Rehabilitation Programme}

There are two major phases which can be identified in the process of rehabilitation.

1. Pre implementation Phase

2. Implementation Phase

In the pre implementation phase, a management philosophy has to be established for Main System Management and then operate the system accordingly at least for 2 Years. The Main purpose of this exercise is to identify true rehabilitation needs of the canal system in relation to both operational as well as structural needs. The management philosophy of an irrigation system could be in a form of an operation guideline such as Water Quota system which will be practiced jointly with the user. These guidelines can be revised and improved and made user-friendly in the course of joint operation. At this pre implementation stage the institutional setup among the users may not be that strong. Therefore, more government sector involvement might be necessary to strengthen the FOs so that at the implementation stage of the rehabilitation, they as a group would be institutionally strong enough to face Participatory Rural Appraisals (PRAs) effectively. At the time of conducting the PRAs, farmers should be knowledgeable enough to identify the real drawback of the systems related to management aspects. Tools such as Participatory Rural Appraisals will effectively work for the identification of rehabilitation needs only if the users are educated enough to face those appraisals productively. Without equipping farmers with the necessary know how on the system related to their functional aspects the appraisals would function only as one way tool.

The Pre implementation phase has to be funded through government budget. Therefore at the pre-implementation phase there is a need for a budget allocation in addition to the normal O\&Mallocation.

Under the MRRP there was no such preimplementation exercise and the water quota system had to be introduced as a parallel activity with the physical rehabilitation. Therefore the feed back from the farmers during PRAs did not properly reflect the true requirements related to water management. Although the water duty was substantially reduced after the rehabilitation phase in System $\mathrm{H}$ in areas where the water quota systems were practiced, duty would have been further reduced if the water quota system was practiced at least for a season prior to the implementation phase of the rehabilitation program.

\section{Conclusion}

The Rehabilitation of New Irrigation Projects must be planned by treating O\&M subsequent to the rehabilitation phase also as an equally 
important challenge of a rehabilitation process. The Water Quota System described in this paper explains the experience gathered during the implementation of a Water Management program under MRRP with the objective of equipping user groups with the know-how on O\&M to meet challenges after the rehabilitation phase. One important feature of the newly introduced system was that the MASL was able to make use of idling human resources available within the farming community in managing the water efficiently in a user friendly manner. Responsibilities of the main Stake Holders of the management process, namely MASL and the Farming Community, were clearly identified and acknowledged by each party in practicing the newly introduced water quota system. The work load of Irrigation Engineers was also reduced because of the effective participation of the users themselves in distributing water. Avenues were also opened for the MASL to introduce incentives for the farmer groups who manage water efficiently. It also facilitate of the introduction of incentive schemes for Management staff too because the Area wise Water Use data are generated automatically in practicing water quota system. Areas of high water consumptions can also identified thereby allowing more realistic regional budgetary allocations for O\&M work. The Practicing of Water Quota System in managing large scale irrigation projects would also act as a catalyst program for farmers to become aware of the importance of having a legal base for water resource development. 